\title{
Investigation of the Effect of Bedding Layer Angle and Tunnel Number on the Stability of Tunnel under Uniaxial Compression Using PFC2D
}

\author{
Vahab Sarfarazi ${ }^{1 *}$, Kaveh Asgari $^{2}$, Mahdiyah Azizian $^{3}$ \\ ${ }^{1}$ Department of Mining Engineering, Hamedan University of Technology, 6516913733 Hamedan, Iran \\ ${ }^{2}$ Department of Mining Engineering, Shahid Bahonar University of Kerman, 76169-14111 Kerman, Iran \\ ${ }^{3}$ Department of Mining Engineering, Tarbiat Modares University, 14115-111 Tehran, Iran \\ * Corresponding author, e-mail: sarfarazi@hut.ac.ir
}

Received: 24 January 2021, Accepted: 30 March 2021, Published online: 21 May 2021

\begin{abstract}
In this paper the effect of bedding layer angle on the stability of tunnel under uniaxial compression have been investigated using particle flow code in two dimensions (PFC2D). For this purpose, numerical rectangle models with dimension of $100 * 100 \mathrm{~mm}$ have been prepared. These models consist of layers with different mechanical properties i.e., concrete layer and gypsum layer. The angle of these layers related to horizontal axis change from $0^{\circ}$ to $90^{\circ}$ with increment of $15^{\circ}$. These models are consisting of one, two and three tunnel. The diameter of tunnel change based on the tunnel number. The tunnel diameter was $6 \mathrm{~m}$, when one tunnel exists in the model. The tunnel diameter was $3 \mathrm{~m}$, when two tunnels exist in the model. The tunnel diameter was $2 \mathrm{~m}$, when three tunnels exist in the model. These models were subjected to uniaxial compression. The results show that tensile cracks are dominant mode of fracture occurred in the models. The joint angle and tunnel number have important effect on the failure pattern and failure strength. Also, the mechanical properties of beddings control the crack growth path. The crack grows through the weak layers when bedding angle was equal to $45^{\circ}$ and $60^{\circ}$, but it intersects the layer for any other bedding angels.
\end{abstract}

Keywords

bedding layer angle, tunnel, PFC2D

\section{Introduction}

Nearly in all cases of underground engineering constructions layered rock masses with sedimentary structure can be seen [1]. As the deposition process begins and continues, layered rock masses form different structures and coupling properties in different directions. Anisotropy is one of main mechanical characteristics of a layered structure rock mass, this property is due to different size of mineral particles in compound state [2]. These kind of structures in the rock mass organized in alignment produce the bedding plane and foliation features. In these bedding planes parameters such as the strength, failure patterns, and deformations are varied in each direction and it is due to of the poor mechanical characteristics of them, this impact becomes a great challenge for the construction of civil engineering. Many investigators such as Colak and Unlu [3] showed that anisotropy of strength of most of sedimentary and metamorphic rocks, such as shale and slate, is strong. All results showed that the rock strength depends on the loading orientation. When the axial compressive stress was almost normal or paralleled to bedding planes, the maximum strengths were usually obtained. While, when the angle between the major stress and bedding planes is located from $30^{\circ}-60^{\circ}$, the minimum strength is found. In addition, in anisotropic rocks, the failure mode also relies on orientation of loading. There are many investigations on the strength anisotropy of rocks. Li et al. [4] ameliorate Griffith's theory of brittle fracture for anisotropic slate, Al-Harthi [5] focused on the sandstone's behavior. They have indicated that, as observed in experiments, relying on the type of failure, either the disc or the ring tests are used to provide the experimental values needed to represent the tensile strength. Pan et al. [6] examined the anisotropy on gneiss and schist, Chen and Hsu [7] investigated strength anisotropy of marble, Xiao et al. [8] worked on anisotropic nature of metamorphic rocks from Greece. In all recent studies, it is obviously 
indicated that minimum strength of anisotropic rocks is at the critical weak plane. Furthermore, results showed that changing of elastic rock parameters like Young's modulus, Poisson's ratio and tensile strength is like the ultimate strength. As the transportation system extend to mountain zones, tunnels and, also, crossing the layered rock mass increased. Because of the impact of rock thickness and inclination angle of joint surface and structural plane, often engineering occurrences such as bedding slip, large deflection under eccentric pressure, support damage and even overall damage and instability of the tunnel happen [9]. The numerical simulation method usually used for the layered surrounding rock tunnel; this method usually simplifies the geological conditions, load conditions, boundary conditions and initial stress field and used to construct the structural models. A more appropriate way to reflect the actual law is the rapid calculation of the computer, also the numerical solution that meets the needs of engineering can be provided. In addition, this method is a good alternative for expensive and complex large-scale field experiments to effectively solve different complex engineering issues [10]. Zhu et al. [11] investigated the stability of tunnel surrounding rock inclination with varied inclination angle of rock layers using the discrete element UDEC software. When the inclination angle was small, the vault was close to bending failure. Xia [12] simulated anisotropic properties of layered rock mass failure by considering the composite types of rock mass failure and bedding failure using the jointed constitutive models provided by FLAC, then analyzed the stability of layered rock mass slope. Song investigates the impact of structural surface distribution properties on the deformation of tunnel surrounding rock using the three-dimensional discrete element procedure (3DEC), then summarized two states of the effect of structural plane line density on tunnel deformation. Wang et al. [13] provided an anisotropic mechanical model of layered rock mass based on the DruckerPrager criterion; this model considering the mechanical properties of the structural plane and bedrock, then the model applied to the calculation and analysis of layered rock mass of underground engineering. the anisotropy of layered rock mass can be better shown by the results. Wang et al. [14] indicated the failure mode and regularity of the gently inclined rock slope of the Qijiang River in Chongqing, then showed that pressure is the major inducement of rock cavity failure. Wang Based on engineering history of the return airway in a coal mine, simulate the deformation and failure of layered composite surrounding rock roadway before and after support, using the finite difference software FLAC3D. Furthermore, the composite double beam coupling mechanism and numerical simulation results of tunnel surrounding rock proposed the corresponding bolt-shotcrete support form [15]. To better comprehension, Tien et al. [16] to clarify mechanism of failure around a tunnel, studied the failure of isotropic rocks, this research provides a good insight from the collapse mode. Wang et al. [17] used RFPA to investigate the mechanism of failure for a circular tunnel in transversely isotropic rock, where the failure process is characterized by the initiation, propagation, and coalescence of cracks around the tunnel. Xu et al. [18] based on the Mohr-Coulomb and maxi-mum tensile-stress criteria established a transversely isotropic elastic-plastic model to define the elastic response and post-peak failure behavior, which was utilized to assess rock mass excavation response in underground openings. Based on the assessing of large scale of different distributed discontinuities, Yang et al. [19] investigated the effect of joint plane angle. In many publications, numerical procedure has been used to provide precious information in assessing of tunnel stability [2022], furthermore, some calculation model achievements have been made [23]. In addition of several major anisotropic mechanical feature, investigation of the layered rock results in proper analysis of stability. Chen et al. [24] conducted several uniaxial and triaxial compression experiments on the slate samples with different inclination angles and based on which a micromechanical damage-friction model was proposed investigated the anisotropic behaviors and failure mechanisms of slate. Niandou et al. [25] based on the failure pattern of Tournemire shale; help each other with some research [26-32], they have indicated that bedding plane dip angle, $\theta$ have a significant impact on the strength and failure pattern of layered rock. Although, many complex excavation projects in anisotropic rock have been investigated, but there are a limited number of cases that includes several sets of anisotropic shear strength simultaneously in one model. Thus, in the present research, to evaluate the tunnel stability in layered rock mass, a specific numerical model including anisotropic shear strength that reflected in experiment tests was utilized. Before analyzing tunnel stability, numerical model validation was conducted between experiment and numerical results. \&en, shear loading process and the anisotropic failure properties shown in experiments were 
reproduced numerically. Thus, the validated model was utilized to assess the stress and deformation of an anisotropic rock tunnel. The aim of this paper is to study the effect of bedding layer with different mechanical properties on the tunnel stability by PFC2D. the number of tunnels is different in various models.

\section{Stages of laboratory tests}

\subsection{Mechanical properties of samples}

To build the gypsum and concrete samples, the gypsum and water mixture was used with a ratio of 2 to 1 . Also, the cement, fine sand and water mixture was used with a ratio of 2:1:1. Brazilian tests were carried out on disc samples. The disc samples have a diameter 54 and the thickness of $27 \mathrm{~mm}$. Fig. 1(a) and (b) shows failure pattern in Brazilian test for gypsum and concrete specimens. Table 1 shows tensile strength of rock like specimens.

\section{Particle Flow Code}

Particle flow code in two dimensions (PFC2D) is a distinct element code that represents the material as a collection of rigid particles which can move separately and interact only at contacts (Potyondy and Cundall [33]). Same as the DEM, a central finite difference method has been used to calculate the movements and interaction forces of particles for contact models, both linear and non-linear contact models with frictional sliding can be used. In this study, the linear contact model has been used, provides an elastic relationship between the relative displacements, and contact forces of particles. To produce a parallel-bonded particle model for PFC2D, using the routines provided, the following micro characteristics should be represented:

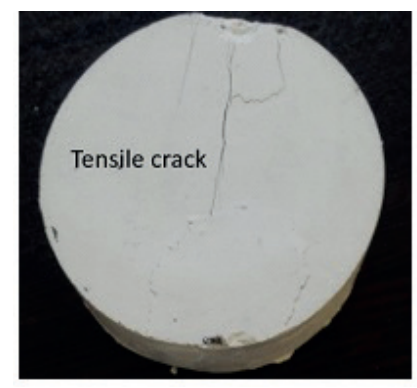

(a)

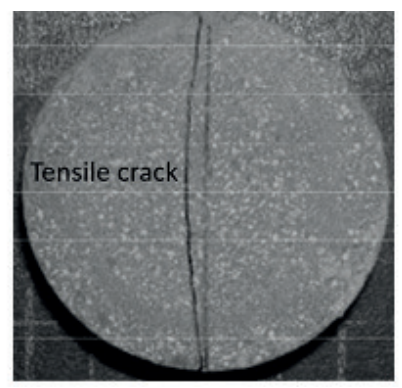

(b)
Fig. 1 a) Failure pattern in gypsum, b) failure pattern in concrete

Table 1 Mechanical properties of specimens

\begin{tabular}{ll}
\hline Tensile strength of concrete & $2.2 \mathrm{MPa}$ \\
\hline Tensile strength of gypsum & $1.3 \mathrm{MPa}$ \\
\hline
\end{tabular}

ball-to-ball contact modulus, stiffness ratio $k n$ over $k s$, ball friction coefficient, parallel normal bond strength, parallel shear bond strength, ratio of standard deviation to mean of bond strength both in normal and shear direction, minimum Ball radius, parallel-bond radius multiplier, parallel-bond modulus, and parallel-bond stiffness ratio. It is essential to set the suitable micro characteristics to be used for the particle assembly, to perform a calibration method. Laboratory model specimens cannot directly represent the particle contact characteristics and bonding properties. The material properties determined by laboratory experimentation are macro-mechanical in nature and it is derived from Continuum behavior. In order to determine the suitable micro-mechanical properties of the numerical models from the macro-mechanical characteristics determined in the laboratory experiments, an inverse modelling procedure was performed. trial-and-error method was one of approaches which used to correlate these two sets of material property [32]. This includes assumption of micro-mechanical property quantities and it is a comparison between the strength and deformation properties of the numerical models and laboratory tests. Then the closest the micro-mechanical property values of simulated macroscopic response to the laboratory tests are selected for the evaluation of shear behavior of non-persistent joint.

\subsection{Preparing and calibrating the numerical model}

The Brazilian test was used to calibrate the tensile strength of specimen in PFC2D model. The standard process of generation of a PFC2D assembly to represent a test model involves four steps: (a) particle generation and packing the particles, (b) isotropic stress installation, (c) floating particle elimination, and (d) bond installation (Potyondy and Cundall, [33]). Adopting the micro-properties listed in Tables 2 and 3, two calibrated PFC particle assembly was created (for gypsum and concrete specimen). The diameter of the Brazilian model were $54 \mathrm{~mm}$. The specimen was made of 6421 particles. The left and right walls was moved toward each other with a low speed of $0.016 \mathrm{~m} / \mathrm{s}$. Fig. 2 shows numerical and experimental out puts of Brazilian test for gypsum and concrete. The results show well matching between experimental test and numerical simulation. The Brazilian tensile strengths have been depicted in Table 4. These mechanical properties are well matching with those of experimental test (Table 1). This shows that models are calibrated correctly. 
Table 2 Micro properties used to represent the gypsum

\begin{tabular}{lccc}
\hline Parameter & Value & Parameter & Value \\
\hline $\begin{array}{l}\text { Type of } \\
\text { particle }\end{array}$ & disc & Stiffness ratio & 2 \\
$\begin{array}{l}\text { density } \\
\begin{array}{l}\text { Minimum } \\
\text { radius }\end{array}\end{array}$ & 3000 & $\begin{array}{c}\text { Particle friction coefficient } \\
\text { contact bond normal strength, } \\
\text { mean (MPa) }\end{array}$ & 0.5 \\
$\begin{array}{l}\text { Size ratio } \\
\begin{array}{l}\text { Porosity ratio } \\
\text { Damping } \\
\text { coefficient }\end{array}\end{array}$ & 0.08 & $\begin{array}{c}\text { contact bond normal strength, SD } \\
\text { (MPa) }\end{array}$ & 2 \\
$\begin{array}{l}\text { Contact young } \\
\text { modulus }(\mathrm{GPa})\end{array}$ & 1.56 & $\begin{array}{c}\text { (MPa) } \\
\text { contact bond shear strength, mean }\end{array}$ & 8 \\
\hline
\end{tabular}

Table 3 Micro properties used to represent the concrete

\begin{tabular}{|c|c|c|c|}
\hline Parameter & Value & Parameter & Value \\
\hline $\begin{array}{l}\text { Type of } \\
\text { particle }\end{array}$ & disc & Stiffness ratio & 3 \\
\hline density & 3600 & Particle friction coefficient & 0.5 \\
\hline $\begin{array}{l}\text { Minimum } \\
\text { radius }\end{array}$ & 0.27 & $\begin{array}{c}\text { contact bond normal strength, } \\
\text { mean }(\mathrm{MPa})\end{array}$ & 12 \\
\hline Size ratio & 1.56 & $\begin{array}{l}\text { contact bond normal strength, SD } \\
\qquad(\mathrm{MPa})\end{array}$ & 2 \\
\hline Porosity ratio & 0.08 & $\begin{array}{l}\text { contact bond shear strength, mean } \\
\qquad(\mathrm{MPa})\end{array}$ & 24 \\
\hline $\begin{array}{l}\text { Damping } \\
\text { coefficient }\end{array}$ & 0.7 & $\begin{array}{l}\text { contact bond shear strength, SD } \\
(\mathrm{MPa})\end{array}$ & 2 \\
\hline $\begin{array}{l}\text { Contact young } \\
\text { modulus }(\mathrm{GPa})\end{array}$ & 8 & & \\
\hline
\end{tabular}

\subsection{Model preparation using Particle Flow Code}

After calibration of PFC2D, a rectangular model consisting bedding layer was prepared. These layers are from gypsum and concrete. The black discs and colored discs are representative of concrete and gypsum layer, respectively. Dimension of rectangular model was $72 \mathrm{~m} * 144 \mathrm{~m}$. The model contains one, two and three tunnel. The diameter of tunnel change based on the tunnel number. The tunnel diameter was $12 \mathrm{~m}$, when one tunnel exists in the model. The tunnel diameter was $6 \mathrm{~m}$, when two tunnels exist in the model. The tunnel diameter was $4 \mathrm{~m}$, when three tunnels exist in the model. The centers of tunnels were situation $72 \mathrm{~m}$ below the ground surface (Figs. 3, 4 and 5). A total of 12,236 disks with a minimum radius of $0.27 \mathrm{~cm}$ were used to make up the rectangular specimen. These models were subjected to uniaxial compression. One measuring circle with diameter of $6 \mathrm{~m}$ was chosen at the tunnel roof and the vertical displacement of discs surrounded in this circle was measured as a vertical displacement of tunnel roof (Figs. 3(a), 4(a) and 5(a)).

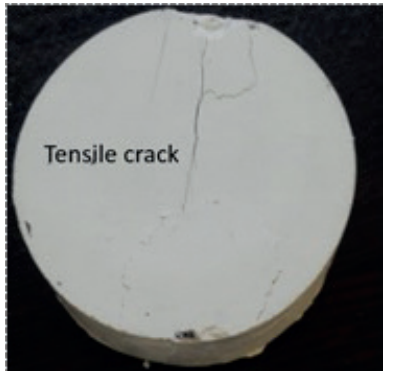

(a)

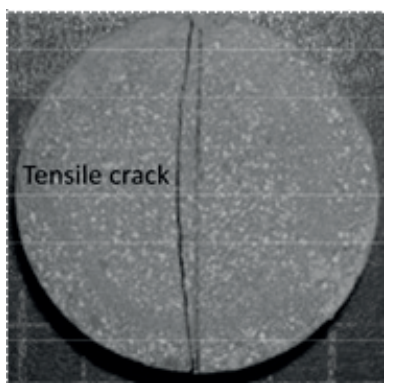

(c)

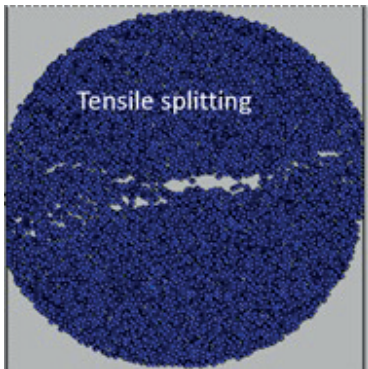

(b)

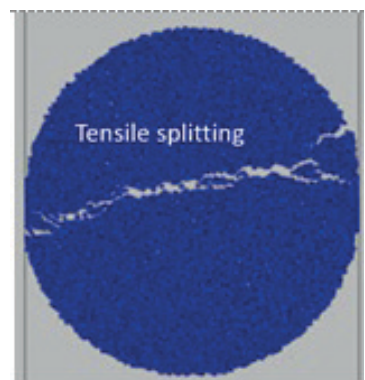

(d)
Fig. 2 a) Experimental Brazilian test on concrete, b) Numerical Brazilian test on concrete, c) experimental Brazilian test on gypsum and d) Numerical Brazilian test on gypsum

Table 4 tensile properties in numerical models

\begin{tabular}{ll}
\hline Tensile strength of concrete $(\mathrm{MPa})$ & 2.4 \\
\hline Tensile strength of gypsum $(\mathrm{MPa})$ & 1.4 \\
\hline
\end{tabular}

\section{Failure behavior of numerical model 4.1 Failure pattern of numerical model}

Figs. 6, 7 and 8 shows failure pattern of models consisting one, two and there tunnel, respectively. Black lines and red lines are representative of shear crack and tensile crack, respectively. Totally, tensile cracks are dominant mode of failure occurred in the models.

\subsubsection{Failure pattern of numerical model consisting one tunnel}

When layer angle was $0^{\circ}$ (Fig. 6(a)), tensile cracks initiates from left side and right side of the tunnel and propagate diagonally till coalescence with left side and right side of the model. When layer angle was $15^{\circ}, 30^{\circ}$ and $90^{\circ}$ (Figs. 6(b), (c) and (g)), tensile cracks initiates from left side and right side of the tunnel and propagate diagonally till coalescence with left side and right side of the model. In this condition, tensile fractures intersect both of the concrete and gypsum layers. When layer angle was $45^{\circ}$ (Fig. 6(d)), tensile cracks initiates from left side and right side of the tunnel and propagate diagonally till coalescence with left side and right side of the model. In this 


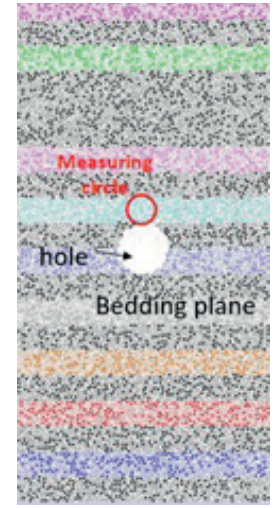

(a)

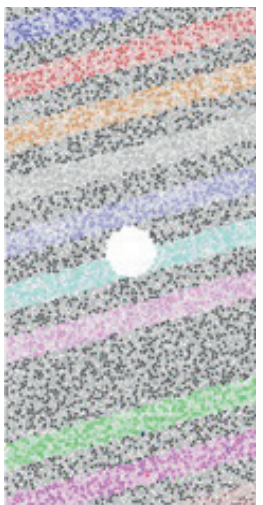

(b)

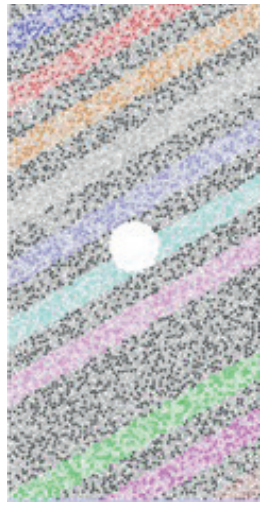

(c)

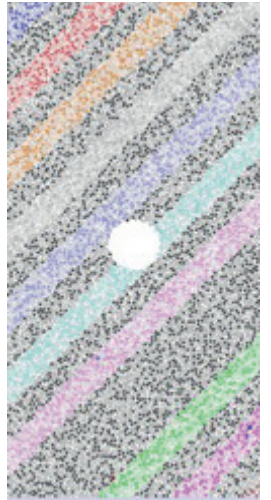

(d)

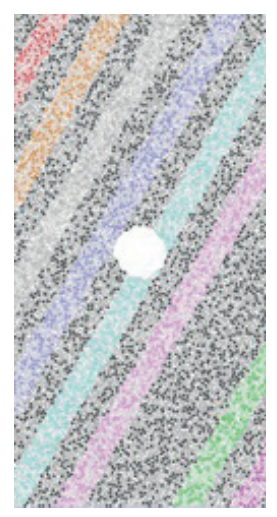

(e)

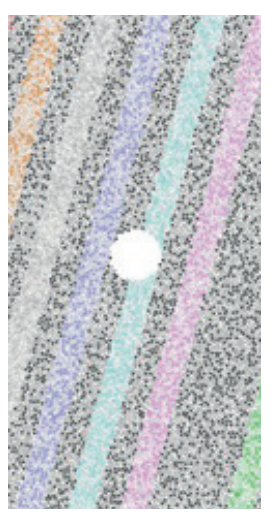

(f)

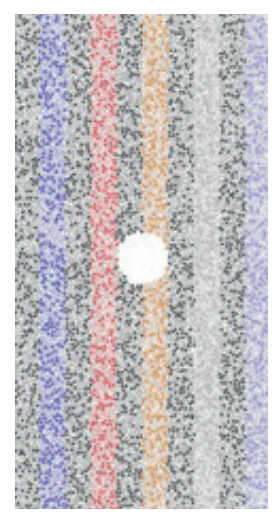

(g)

Fig. 3 Model consisting one hole with beddings angle of a) $0^{\circ}$, b) $15^{\circ}$, c) $30^{\circ}$, d) $45^{\circ}$, e) $60^{\circ}$, f) $75^{\circ}$, g) $90^{\circ}$

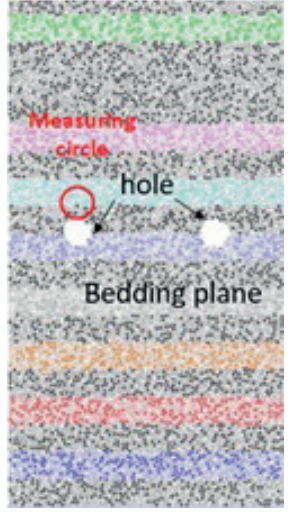

(a)

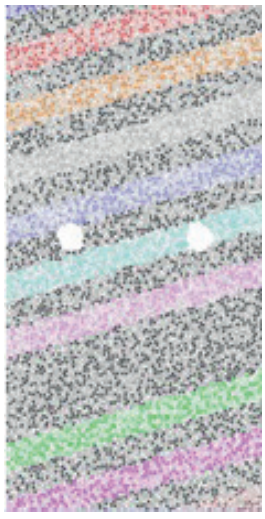

(b)

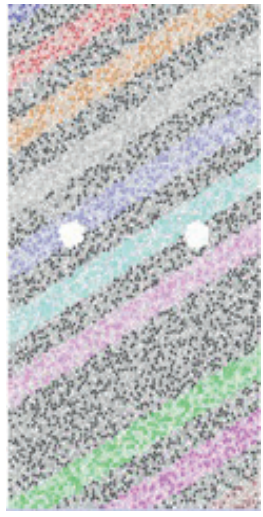

(c)

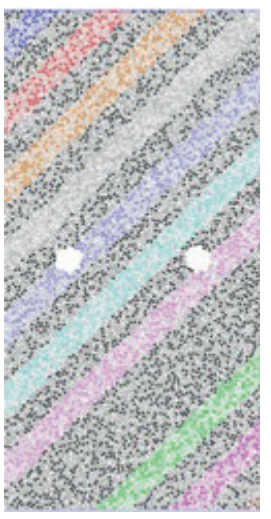

(d)

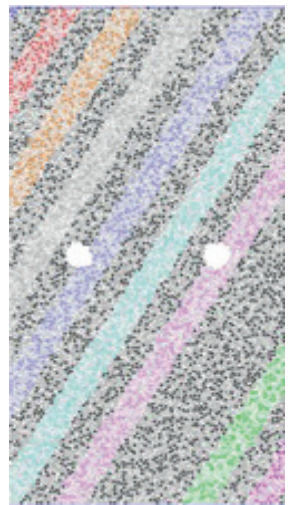

(e)

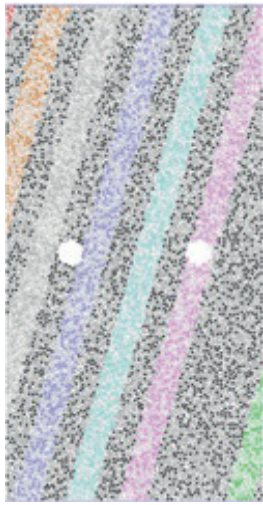

(f)

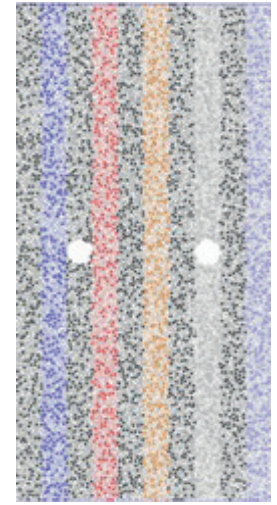

(f)

Fig. 4 Model consisting two holes with bedding angles of a) $0^{\circ}$, b) $15^{\circ}$, c) $30^{\circ}$, d) $45^{\circ}$, e) $60^{\circ}$, f) $75^{\circ}$, g) $90^{\circ}$ 


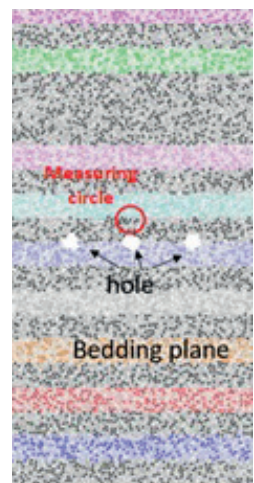

(a)

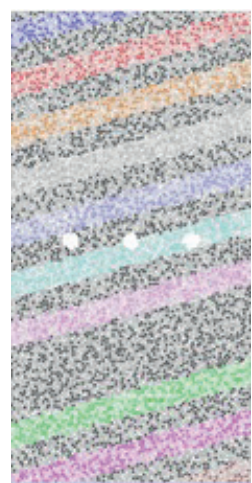

(b)

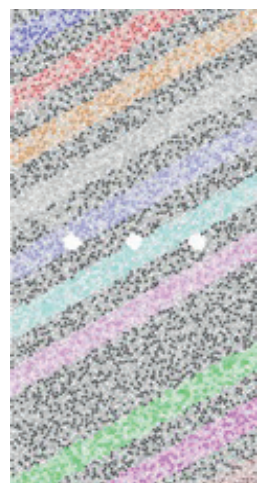

(c)

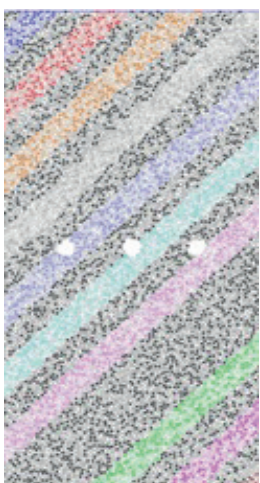

(d)

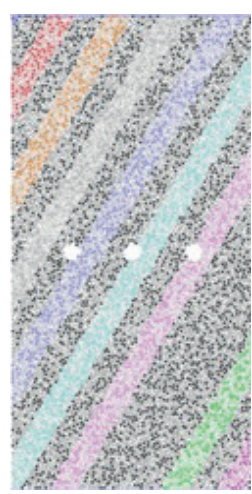

(e)

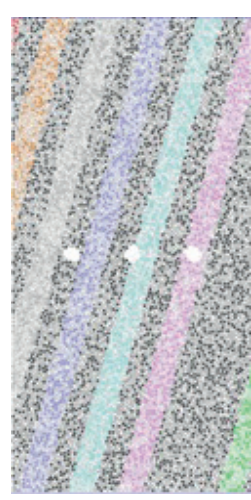

(f)

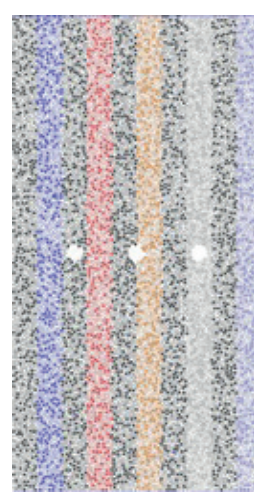

(g)

Fig. 5 Model consisting three holes with bedding angles of a) $0^{\circ}$, b) $15^{\circ}$, c) $30^{\circ}$, d) $45^{\circ}$, e) $60^{\circ}$, f) $75^{\circ}$, g) $90^{\circ}$

condition, tensile fractures go through the gypsum layers. When layer angle was $60^{\circ}$ (Fig. 6€), tensile cracks initiates from left side and right side of the tunnel and propagate diagonally till coalescence with left side and right side of the model. In this condition, tensile fractures go through the gypsum layers. The number of tensile cracks in this condition was less than the condition where the layer angle was $45^{\circ}$. When layer angle was $75^{\circ}$ (Fig. 3(f)), tensile cracks initiates from left side and right side of the tunnel and propagate diagonally till coalescence with left side and right side of the model. In this condition, tensile fractures go through the gypsum layers.

\subsubsection{Failure pattern of numerical model consisting two tunnels}

When layer angle was $0^{\circ}, 15^{\circ}, 30^{\circ}$ and $90^{\circ}$ (Figs. 7(a), (b), (c) and (g)), tensile cracks initiates from left side and right side of the tunnel and propagate diagonally till coalescence with left side and right side of the model. When layer angle was $45^{\circ}, 60^{\circ}$ and $75^{\circ}$ (Figs. 7(d), (e) and (f)), tensile cracks initiates from left side and right side of the tunnel and propagate diagonally till coalescence with left side and right side of the model. In these conditions, tensile fractures go through the gypsum layers.

\subsubsection{Failure pattern of numerical model consisting three tunnels}

When layer angle was $0^{\circ}, 15^{\circ}, 30^{\circ}$ and $90^{\circ}$ (Figs. 8(a), (b), (c) and (g)), tensile cracks initiates from left side and right side of the tunnel and propagate diagonally till coalescence with left side and right side of the model. When layer angle was $45^{\circ}, 60^{\circ}$ and $75^{\circ}$ (Figs. 8(d), (e) and (f)), tensile cracks initiates from left side and right side of the tunnel and propagate diagonally till coalescence with left side and right side of the model. In these conditions, tensile fractures go through the gypsum layers.

\subsection{Compressive strength of numerical model}

Fig. 9 shows the effect of layer angle on the compressive strength of numerical models consisting one, two and three tunnels. The compressive strength has minimum value when layer angels were 45 and 60 degree. This rate has been fixed for each tunnel number. The compressive strength was increased by increasing the tunnel number.

\subsection{Vertical displacement of tunnel roof of numerical model}

Fig. 10 shows the effect of layer angle on the vertical displacement of tunnel roof. These results are depicted for 


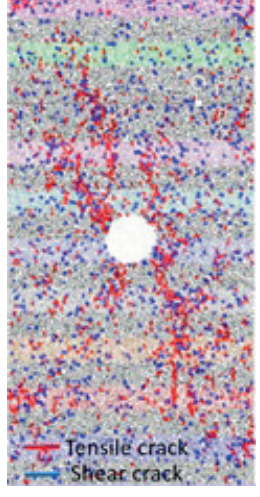

(a)

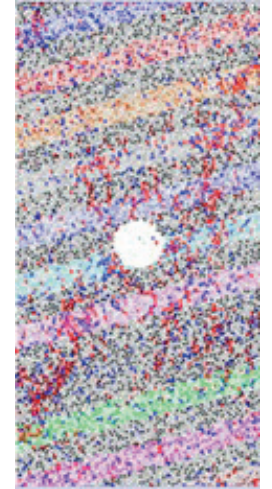

(b)

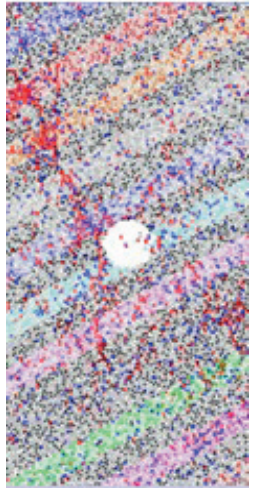

(c)

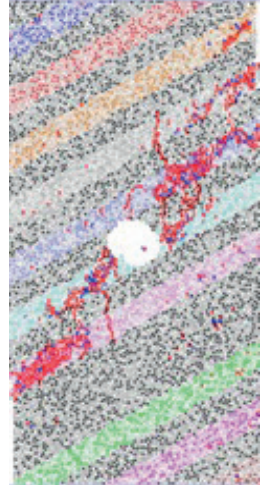

(d)

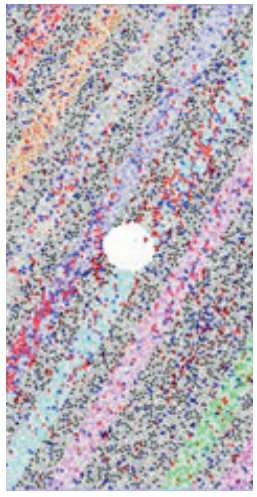

(e)

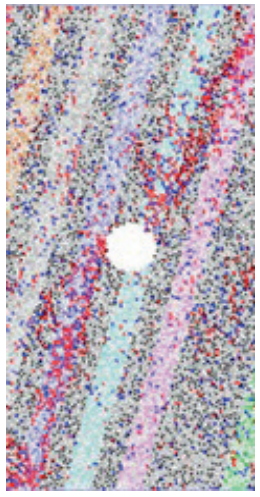

(f)

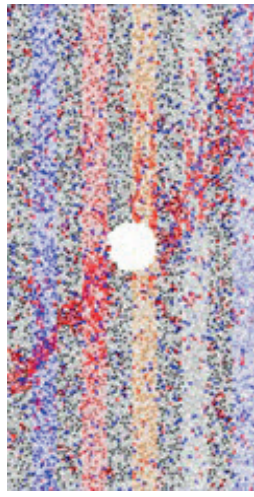

(g)

Fig. 6 Failure pattern of models consisting one holes with bedding angles of a) $0^{\circ}$, b) $15^{\circ}$, c) $30^{\circ}$, d) $45^{\circ}$, e) $60^{\circ}$, f) $75^{\circ}$, g) $90^{\circ}$

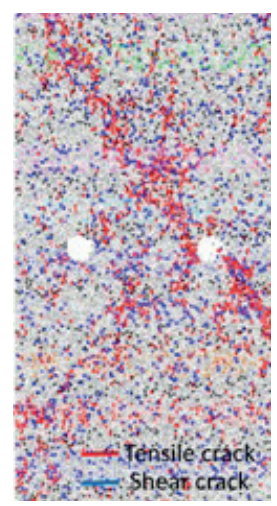

(a)

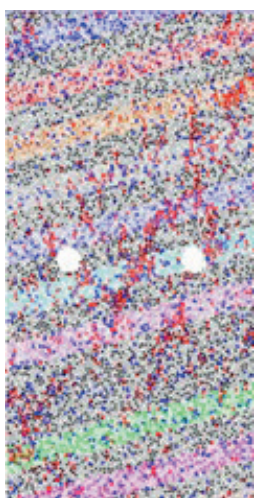

(b)

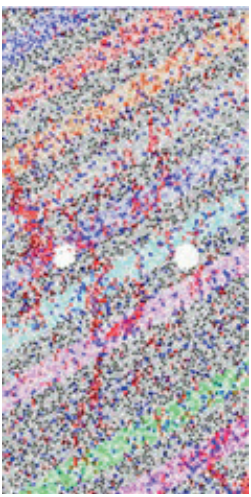

(c)

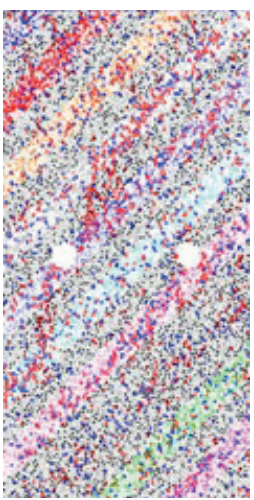

(d)

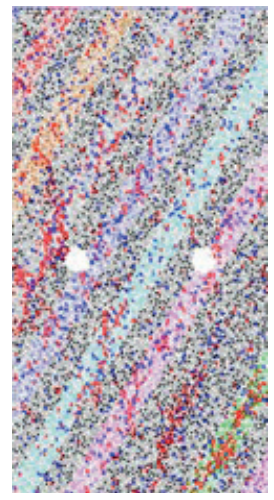

(e)

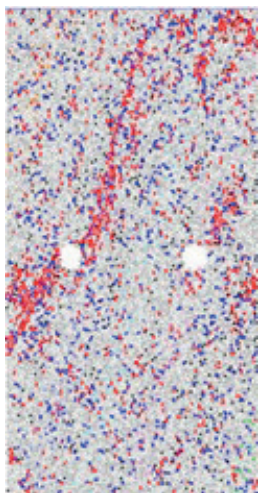

(f)

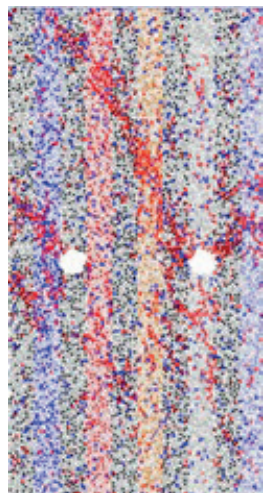

(g)

Fig. 7 Failure pattern of models consisting two holes with bedding angles of; a) $0^{\circ}$, b) $15^{\circ}$, c) $30^{\circ}$, d) $45^{\circ}$, e) $60^{\circ}$, f) $75^{\circ}$, g) $90^{\circ}$ 


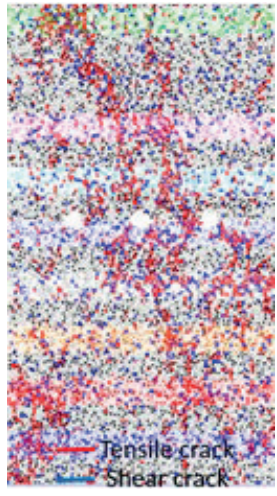

(a)

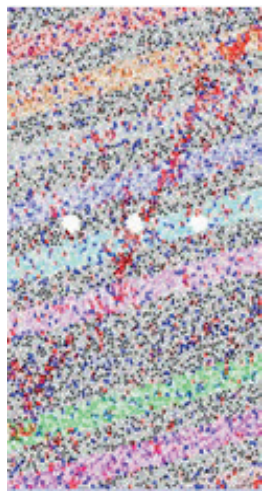

(b)

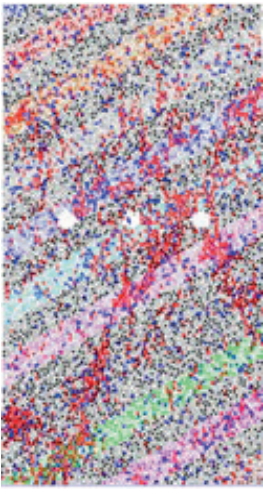

(c)

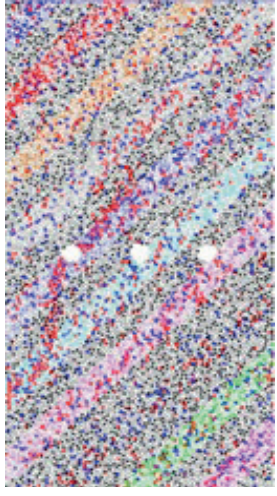

(d)

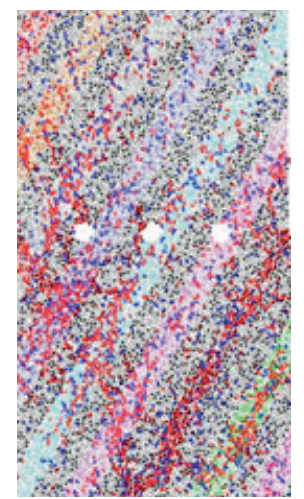

(e)

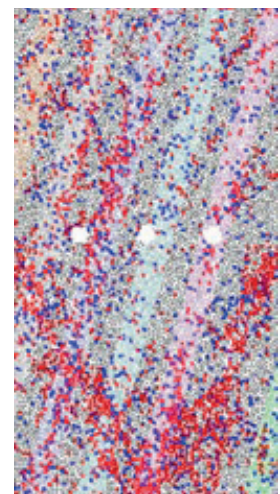

(f)

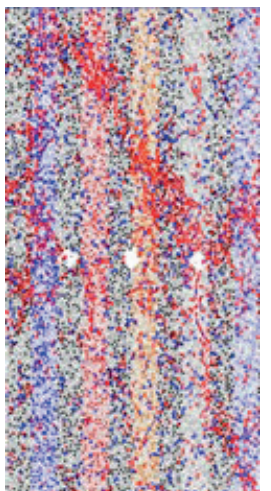

(g)

Fig. 8 Failure pattern of models consisting three holes with bedding angles of a) $0^{\circ}$, b) $15^{\circ}$, c) $30^{\circ}$, d) $45^{\circ}$, e) $60^{\circ}$, f) $75^{\circ}$, g) $90^{\circ}$

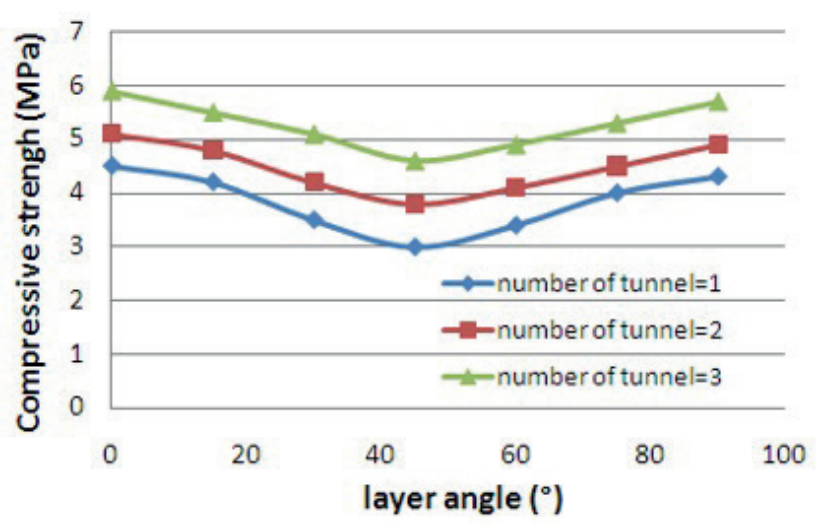

Fig. 9 the effect of layer angle on the compressive strength of numerical models

numerical models consisting one, two and three tunnels. The vertical displacement has maximum value when layer angels were $45^{\circ}$ and $60^{\circ}$. This rate has been fixed for each tunnel number. The vertical displacement was increased by decreasing the tunnel number.

\section{Conclusions}

- When layer angle was $0^{\circ}$, tensile cracks initiates from left side and right side of the tunnel and propagate diagonally till coalescence with left side and

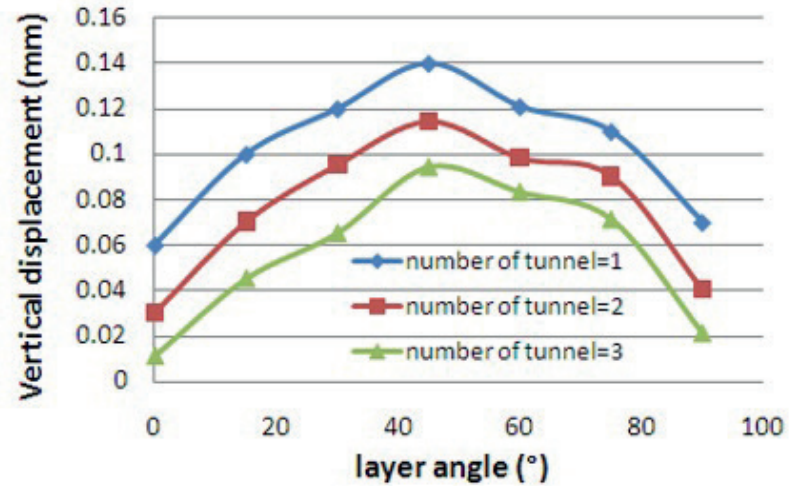

Fig. 10 the effect of layer angle on the vertical displacement of tunnel roof

right side of the model. When layer angle was $15^{\circ}$, $30^{\circ}$ and $90^{\circ}$, tensile cracks initiates from left side and right side of the tunnel and propagate diagonally till coalescence with left side and right side of the model. In this condition, tensile fractures intersect both of the concrete and gypsum layers. When layer angle was $45^{\circ}$, tensile cracks initiates from left side and right side of the tunnel and propagate diagonally till coalescence with left side and right side of the model. In this condition, tensile fractures go through the gypsum layers. When layer angle was $60^{\circ}$, 
tensile cracks initiates from left side and right side of the tunnel and propagate diagonally till coalescence with left side and right side of the model. In this condition, tensile fractures go through the gypsum layers. The number of tensile cracks in this condition was less than the condition where the layer angle was $45^{\circ}$. When layer angle was $75^{\circ}$, tensile cracks initiates from left side and right side of the tunnel and propagate diagonally till coalescence with left side and right side of the model. In this condition, tensile fractures go through the gypsum layers.

\section{References}

[1] Zhang, X., Hu, D., Li, J., Pan, J., Xia, Y., Tian, Y. "Investigation of rock breaking mechanism with TBM hob under traditional and freeface condition", Engineering Fracture Mechanics, 242, Article No. 107432, 2021.

https://doi.org/10.1016/j.engfracmech.2020.107432

[2] An, Z., Di, Q., Wu, F., Wang, G., Wang, R. "Geophysical exploration for a long deep tunnel to divert water from the Yangtze to the Yellow River, China", Bulletin of Engineering Geology and the Environment,71(1), pp. 195-200, 2012. https://doi.org/10.1007/s10064-011-0358-7

[3] Colak, K., Unlu, T. "Effect of transverse anisotropy on the HoekBrown strength parameter 'mi' for intact rocks", International Journal of Rock Mechanics and Mining Sciences, 41(6), pp. 10451052, 2004.

https://doi.org/10.1016/j.ijrmms.2004.04.004

[4] Li, X., Wang, S., Ge, S., Malekian, R., Li, Z. "Numerical simulation of rock fragmentation during cutting by conical picks under confining pressure", Comptes Rendus Mécanique, 345, pp. 890-902, 2017.

https://doi.org/10.1016/j.crme.2017.09.004

[5] A1-Harthi, A. A. "Effect of planar structures on the anisotropy of Ranyah sandstone, Saudi Arabia", Engineering Geology, 50, pp. 49-57, 1998.

https://doi.org/10.1016/S0013-7952(97)00081-1

[6] Pan, Y., Liu, Q., Peng, X., Liu, Q., Liu, J. Huang, X., Cui, X., Cai, T. "Full-Scale Linear Cutting Tests to Propose Some Empirical Formulas for TBM Disc Cutter Performance Prediction", Rock Mechanics and Rock Engineering, 52, pp. 4763-4783, 2019. https://doi.org/10.1007/s00603-019-01865-x

[7] Chen, C. S., Hsu, S. C. "Measurement of Indirect Tensile Strength of Anisotropic Rocks by the Ring Test", Rock Mechanics and Rock Engineering, 34(4), pp. 293-321, 2001. https://doi.org/10.1007/s006030170003

[8] Xiao, N., Zhou, X.-P., Gong, Q.-M. "The modelling of rock breakage process by TBM rolling cutters using 3D FEM-SPH coupled method", Tunnelling and Underground Space Technology, 61, pp. 90-103, 2017.

https://doi.org/10.1016/j.tust.2016.10.004
- The compressive strength has minimum value when layer angels were 45 and 60 degree. This rate has been fixed for each tunnel number.

- The compressive strength was increased by increasing the tunnel number.

- The vertical displacement has maximum value when layer angels were 45 and 60 degree. This rate has been fixed for each tunnel number.

- The vertical displacement was increased by decreasing the tunnel number.

[9] Zhang, X., Xia, Y., Tan, Q., Wu, D. "Comparison Study on the Rock Cutting Characteristics of Disc Cutter under Free-face-assisted and Conventional Cutting Methods", KSCE Journal of Civil Engineering, 22(10), pp. 4155-4162, 2018. https://doi.org/10.1007/s12205-018-0577-6

[10] Elmo, D., Stead, D. "An Integrated Numerical Modelling-Discrete Fracture Network Approach Applied to the Characterization of Rock Mass Strength of Naturally Fractured Pillars", Rock Mechanics and Rock Engineering, 43, pp. 3-19, 2010. https://doi.org/10.1007/s00603-009-0027-3

[11] Zhu, X., Liu, W., He, X. "The investigation of rock indentation simulation based on discrete element method", KSCE Journal of Civil Engineering, 21(4), pp. 1201-1212, 2017. https://doi.org/10.1007/s12205-016-0033-4

[12] Xia, B.-W. "Deformation characteristic and stability analyses of layered rockmass", Hydrogeology and Engineering Geology, 37(04), pp. 48-52, 2010.

[13] Wang, Y., Ding, W., Jia, S., Zou, C. "Anisotropic Model of Layered Rock Mass Considering Characteristics of Structural Interface", Journal of Highway and Transportation Research and Development, 31(10), pp. 85-92, 2017. https://doi.org/10.3969/j.issn.1002-0268.2014.10.014

[14] Wang, L., Tang, H., Tang, F., Ye, S. "Failure mechanism of gently inclined bedding rock mass slopes with complex fissures", Chinese Journal of Geotechnical Engineering, 39(12), pp. 2253-2260, 2017.

[15] Wang, H., Yang, S., Niu, S. "Deformation Mechanism of Roadway with Layered Compound Strata and Its Control Technology", Journal of Taiyuan University of Technology, 47(5), pp. 605-612, 2016.

[16] Tien, Y. M., Kuo, M. C., Juang, C. H. "An experimental investigation of the failure mechanism of simulated transversely isotropic rocks", International Journal of Rock Mechanics and Mining Sciences, 43(8), pp. 1163-1181,2006.

https://doi.org/10.1016/j.ijrmms.2006.03.011

[17] Wang, S. Y., Sloan, S. W., Tang, C. A., Zhu, W. C. "Numerical simulation of the failure mechanism of circular tunnels in transversely isotropic rock masses", Tunnelling and Underground Space Technology, 32(11), pp. 231-244,2012. https://doi.org/10.1016/j.tust.2012.07.003 
[18] Xu, D.-P, Feng, X.-T, Chen, D.-F., Zhang, C.-Q., Fan, Q.-X. "Constitutive representation and damage degree index for the layered rock mass excavation response in underground openings", Tunnelling and Underground Space Technology, 64, pp. 133-145, 2017. https://doi.org/10.1016/j.tust.2017.01.016

[19] Yang, T., Wang, P., Xu, T., Yu, Q., Zhang, P., Shi, W., Hu, G. "Anisotropic characteristics of jointed rock mass: A case study at Shirengou iron ore mine in China", Tunnelling and Underground Space Technology, 48, pp. 129-139, 2015. https://doi.org/10.1016/j.tust.2015.03.005

[20] Liu, H., Li, P., Liu, J. "Numerical investigation of underlying tunnel heave during a new tunnel construction", Tunnelling and Underground Space Technology, 26(2), pp. 276-283, 2011. https://doi.org/10.1016/j.tust.2010.10.002

[21] Cho, J.-W., Jeon, S., Jeong, H.-Y., Chang, S.-H. "Evaluation of cutting efficiency during TBM disc cutter excavation within a Korean granitic rock using linear-cutting-machine testing and photogrammetric measurement", Tunnelling and Underground Space Technology, 35, pp. 37-54, 2013. https://doi.org/10.1016/j.tust.2012.08.006

[23] Lin, Q., Cao, P., Cao, R. "Experimental investigation of jointed rock breaking under a disc cutter with different confining stresses", Comptes Rendus Mécanique, 346(9), pp. 833-843, 2018. https://doi.org/10.1016/j.crme.2018.06.012

[24] Chen, Y.-F., Wei, K., Liu, W., Hu, S.-H., Hu, R., Zhou, C.-B, "Experimental Characterization and Micromechanical Modelling of Anisotropic Slates", Rock Mechanics and Rock Engineering, 49(9), pp. 3541-3557, 2016.

https://doi.org/10.1007/s00603-016-1009-x

[25] Niandou, H., Shao, J. F., Henry, J. P., Fourmaintraux, D. "Laboratory investigation of the mechanical behavior of Tournemire shale", International Journal of Rock Mechanics and Mining Sciences, 34(1), pp. 3-16, 1997.

https://doi.org/10.1016/S1365-1609(97)80029-9
[26] Sarfarazi, V., Ghazvinian, A., Schubert, W., Nejati, H. R., Hadei, R. "A New Approach for Measurement of Tensile Strength of Concrete", Periodica Polytechnica Civil Engineering, 60(2), pp. 199-203, 2016. https://doi.org/10.3311/PPci.8328

[27] Yaylac1, M., Avcar, M. "Finite element modeling of contact between an elastic layer and two elastic quarter planes", Computers and Concrete, 26(2), pp. 107-114, 2020. https://doi.org/10.12989/cac.2020.26.2.107

[28] Uzun Yaylac1, E., Yaylacı, M., Ölmez, H. Birinci, A. "Artificial neural network calculations for a receding contact problem", Computers and Concrete, 25(6), pp. 89-99, 2020. https://doi.org/10.12989/cac.2020.25.6.551

[29] Yaylac1, M., Terzi, C., Avcar, M. "Numerical analysis of the receding contact problem of two bonded layers resting on an elastic half plane", Structural Engineering and Mechanics, 72(6), pp. 67-81, 2019.

https://doi.org/10.12989/SEM.2019.72.6.775

[30] Oner, E., Yaylaci, M., Birinci, A. "Analytical solution of a contact problem and comparison with the results from FEM", Structural Engineering and Mechanics, 54(4), pp. 607-622, 2015.

https://doi.org/10.12989/sem.2015.54.4.607

[31] Yaylaci, M., Birinci, A. "The receding contact problem of two elastic layers supported by two elastic quarter planes", Structural Engineering and Mechanic, 48(2), pp. 241-255, 2013. https://doi.org/10.12989/sem.2013.48.2.241

[32] Yaylaci, M. "The investigation crack problem through numerical analysis", Structural Engineering and Mechanics, 57(6), pp. 11431156, 2016.

https://doi.org/10.12989/sem.2016.57.6.1143

[33] Potyondy, D. O., Cundall, P. A. "A bonded-particle model for rock", International Journal of Rock Mechanics and Mining Sciences, 41(8), pp. 1329-1364, 2004.

https://doi.org/10.1016/j.jirmms.2004.09.011 